\title{
A STATE SPACE FORMULATION FOR THE EVALUATION OF THE POUNDING FORCES DURING EARTHQUAKE
}

\author{
George Bogdan NICA - Assistant Proffesor, PhD, Technical University of Civil Engineering, $\bowtie$ : george.nica@utcb.ro \\ Vasile CALOFIR - Lecturer, PhD, Politehnica University of Bucharest, $\triangle$ : vasile.calofir@upb.ro \\ Ioan Cezar CORÂCI - Associate Professor, PhD, Politehnica University of Bucharest, $\square$ : iccoraci@gmail.com
}

\begin{abstract}
In recent years, the pounding effect during earthquake is a subject of high significance for structural engineers. In this paper, a state space formulation of the equation of motion is used in a MATLAB code. The pounding forces are calculated using nonlinear viscoelastic impact element. The numerical study is performed on SDOF structures subjected by 1940 EL-Centro and 1977 Vrancea N-S recording. While most of the studies available in the literature are related to Newmark implicit time integration method, in this study the equations of motion in state space form are direct integrated. The time domain is chosen instead of the complex one in order to catch the nonlinear behavior of the structures. The physical nonlinear behavior of the structures is modeled according to the Force Analogy Method. The coupling of the Force Analogy Method with the state space approach conducts to an explicit time integration method. Consequently, the collision is easily checked and the pounding forces are taken into account into the equation of motion in an easier manner than in an implicit integration method. A comparison with available data in the literature is presented.
\end{abstract}

Keywords: SDOF, state space, force analogy method, nonlinear viscoelastic, gap

\section{Introduction}

During seismic actions a new problem arises in the case of tall buildings in urban areas, namely pounding of adjacent buildings. This phenomenon consists of collisions at different levels due the different dynamic characteristics of the adjacent structures. Pounding failure of structures is illustrated in many papers. The work of Dhakal et. al. [1] reveals the pounding damages observed in the 2011 Christchurch earthquake. Also, the recent work of Shrestha and Hao [2] illustrate the pounding damages observed in the 2015 Gorkha Earthquake.

The common procedure for pounding phenomenon idealization involves using single degree of freedom (SDOF) or multi degree of freedom (MDOF) models. In these models the mass of each story is considered lumped. The study of Anagnostopoulos [3] is one of the first papers using stick models. Recent work of Mate et al. [4],[5],[10] and the studies of Jankowski [6-9] are also performed on stick models. The time integration method used in these studies is implicit. The previous study of Nica and Pricopie [11] presents an explicit time integration methodology based on central finite difference, and compares the data obtained using the stereomechanics approach with the ones from the nonlinear viscoelastic impact element.

In this paper, two idealized SDOF structures are acted by El-Centro recording and their nonlinear response is obtained using a direct integration method of the equations in the state-space form, i.e. an explicit code developed in MATLAB. The time domain is chosen instead of the complex one in order to catch the physical nonlinear behavior of the structures. The Force Analogy Method is chosen to represent the plastic displacement. The pounding forces between the two SDOF structures are evaluated using the nonlinear viscoelastic impact element model. The numerical data is compared in terms displacement time-history, pounding forces, collision time and total transferred momentum.

\section{State Space formulation: Nonlinear seismic response of the reference SDOF structures}

In this chapter the state space formulation is presented. The seismic response of the two reference structures is obtained, in order to validate the results. First, the two structures are considered independent, namely no contact arises between the structures. 


\subsection{State Space formulation of the equations of motion}

The state space formulation is a mathematical model of a physical system. The input, output and state variables are related by first order differential equations. Thus, the state space is a euclidian space in which the state variables are the variables on the axes. A vector within that space represents the state of the system.

The equation of motion describing the structures is a second order differential equation. Equation (1) represents the equation of motion for a SDOF system, where $M, C, K$ represent the mass, damping coefficient and stiffness, $u, \dot{u}, \ddot{u}$ represent the displacement, velocity and acceleration, and $p$ represent the exterior loads. In the state space form, the number of states is the equal to the order of the differential equation. Denote by $X$ the state vector, containing the displacement $u$ and the velocity $\dot{u}(2)$. Introducing (2) in (1), one obtains the acceleration as a function of $X$ and the exterior loads $p$ (3). Also the second order differential equation (1) is transformed in two first order differential equations (4).

$$
\begin{aligned}
& M \ddot{u}+C \dot{u}+K u=p \\
& X=\left[\begin{array}{l}
u \\
\dot{u}
\end{array}\right] \leftrightarrow \dot{X}=\left[\begin{array}{l}
\dot{u} \\
\ddot{u}
\end{array}\right] \\
& \ddot{u}=M^{-1}(p-C \dot{u}-K u) \leftrightarrow\left[\begin{array}{ll}
-M^{-1} K & -M^{-1} C
\end{array}\right]\left[\begin{array}{l}
u \\
\dot{u}
\end{array}\right]+M^{-1} p \leftrightarrow \ddot{u} \\
& =C X+D p \\
& \dot{X}=\left[\begin{array}{l}
\dot{u} \\
\ddot{u}
\end{array}\right]=\left[\begin{array}{cc}
0 & \mathrm{I} \\
-M^{-1} K & -M^{-1} C
\end{array}\right]\left[\begin{array}{l}
u \\
\dot{u}
\end{array}\right]+\left[\begin{array}{c}
0 \\
M^{-1}
\end{array}\right] p \leftrightarrow \dot{X}=A X+B p
\end{aligned}
$$

The traditional notation of the state space representation is through the matrices $A, B, C, D(5)$ :

$$
\begin{aligned}
& \Sigma_{A, B, C, D}=\left\{\begin{array}{l}
\dot{X}=A X+B p \\
Y=C X+D p
\end{array} \quad\right. \text { where } \\
& A=\left[\begin{array}{cc}
0 & \mathrm{I} \\
-M^{-1} K & -M^{-1} C
\end{array}\right], \quad B=\left[\begin{array}{c}
0 \\
M^{-1}
\end{array}\right], \quad C=\left[\begin{array}{ll}
-M^{-1} K & -M^{-1} C
\end{array}\right], \\
& \text { or }\left[\begin{array}{ll}
A & B \\
C & D
\end{array}\right]=\left[\begin{array}{ccc}
0 & \mathrm{I} & 0 \\
-M^{-1} K & -M^{-1} C & M^{-1} \\
-M^{-1} K & -M^{-1} C & M^{-1}
\end{array}\right]
\end{aligned}
$$

Equation (4) is a first order linear matrix equation, also called the continous state spate equation of motion. Thus, in general, the solution for any $t \geq t_{0}$, where $t_{0}$ represents the time when the initial velocity and displacement are given, can be written as [13]:

$$
\begin{aligned}
& X(t)=e^{A\left(t-t_{0}\right)} X\left(t_{0}\right)+e^{A t} \int_{t_{0}}^{t} e^{-A s} B p(s) d s \rightarrow \text { for } t_{0}=0 \rightarrow \\
& X(t)=e^{A t} X_{0}+\int_{t_{0}}^{t} e^{A(t-s)} B p(s) d s
\end{aligned}
$$

In the analysis of linear structures subjected to arbitrary dynamic loads the complex domain representation generally leads to the most convenient solution. It must be emphasized that since the principle of superposition is employed in the derivation of these techniques, they may be employed only with linear systems, i.e. for the systems for which the properties $M, C, K$ remain constant during the response. In the case of structures subjected to earthquake motion, severe damages (nonlinearity) occur. This is the reason why the time domain is employed generally in the nonlinear structural analysis. In order to use the step-by-step time integration procedures, the displacement vector is regarded as a combination of the elastic and plastic displacement. 


\subsection{Nonlinear response of the reference SDOF structures}

The Force Analogy Method presented in [13],[14] is used in this study. In this method, the resisting force term in the equation of motion $(K \tilde{u})$, which is related to the physical nonlinearity of the equation, is regarded as the difference between the resisting forces coresponding to a total elastic response $u(t)$ and the forces producing a plastic displacement $u$ " $(t)$. Thus, the initial stiffness is kept constant, and the displacement vector is split in two components, according to equation (8):

$$
\begin{aligned}
& M \ddot{u}+C \dot{u}+K \tilde{u}=p, \quad \text { where } \\
& \tilde{u}(t)=u(t)-u "(t) \\
& p(t)=-M a(t), \quad a(t)-\text { ground acceleration } \\
& M \ddot{u}+C \dot{u}+K u=-M a(t)+K u^{\prime \prime}(t)
\end{aligned}
$$

Changing the displacement, not the stiffness, is the basic concept of the force analogy method. Figure 1 illustrates the concept of the force analogy method, and introduces the member force recovery matrix $K_{P}$ and member restoring force matrix $K_{R}$ [13]. The plastic rotation at the base of the cantilever beam is denoted by $\theta^{\prime \prime}$ and the goal is to find a relation between the inelastic moment $M "$ due to inelastic displacement and $u$ ". To represent the permanent deformation $u$ " as a force one will imagine that a force is applied to restore the structural displacement back to its original position.
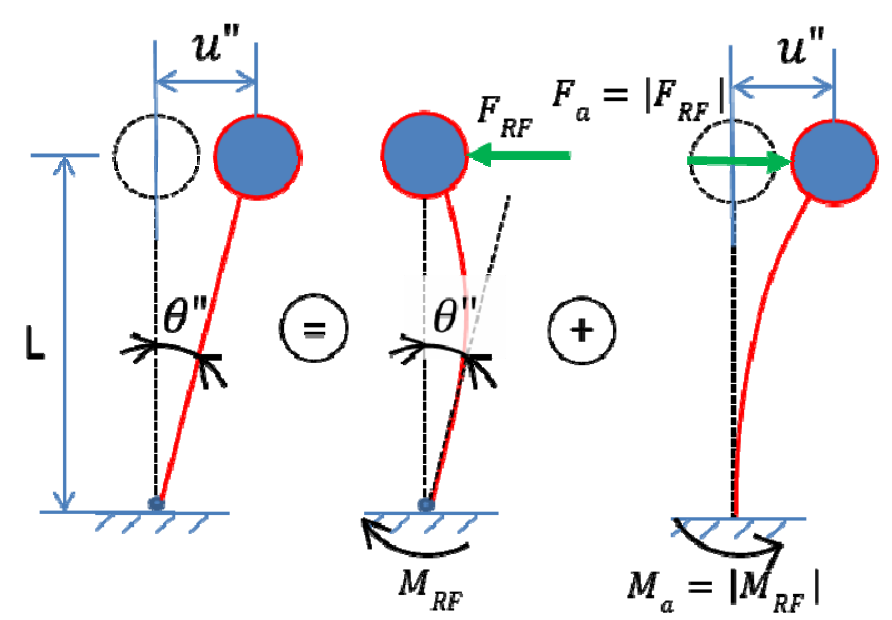

a

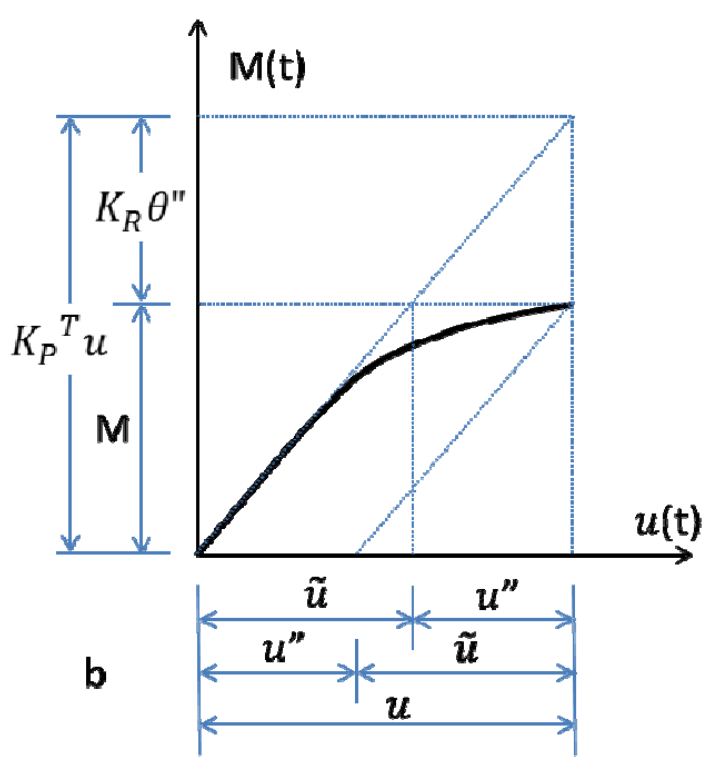

Fig 1 - a) Force Analogy Method for SDOF [14] b) Moment at different level of structural displacement [13]

$$
\begin{aligned}
F_{R F}=K u^{\prime \prime}= & -\frac{3 E I}{L^{3}} u^{\prime \prime} \stackrel{u^{\prime \prime}=L \theta^{\prime \prime}}{\longrightarrow} F_{R F}=-\frac{3 E I}{L^{2}} \theta^{\prime \prime} \leftrightarrow K_{P} \\
& =\frac{3 E I}{L^{2}} \\
M_{R F}=F_{R F} L & =-\frac{3 E I}{L} \theta^{\prime \prime} \leftrightarrow K_{R}=\frac{3 E I}{L}
\end{aligned}
$$

Equations (9) and (10) will be used in eq. (8) written in state space form (11). With the notation from eq. (2), one will obtain eq. (11) in the same manner as eq. (4) was obtained.The solution (6) is further used in (12) and discretized with $\Delta t=t_{k+1}-t_{k}$ to obtain eq. (13). For $t_{k} \leq s<t_{k+1}$, using Delta forcing function to represent the ground acceleration $a(s)$ and inelastic displacement $u "(s)$, one will obtain eq. (15):

$\dot{X}=\left[\begin{array}{c}\dot{u} \\ \ddot{u}\end{array}\right]=\left[\begin{array}{cc}0 & \mathrm{I} \\ -M^{-1} K & -M^{-1} C\end{array}\right]\left[\begin{array}{l}u \\ \dot{u}\end{array}\right]+\left[\begin{array}{c}0 \\ -1\end{array}\right] a+\left[\begin{array}{c}0 \\ M^{-1} K\end{array}\right] u^{\prime \prime} \leftrightarrow \dot{X}=A X+B a+F_{p}^{c} u^{\prime \prime}$ 


$$
\begin{aligned}
& X(t)=e^{A\left(t-t_{0}\right)} X\left(t_{0}\right)+e^{A t} \int_{t_{0}}^{t} e^{-A s}\left[B a(s)+F_{p}^{c} u^{\prime \prime}(s)\right] d s \\
& X_{k+1}=e^{A \Delta t} X_{k}+e^{A t_{k+1}} \int_{t_{k}}^{t_{k+1}} e^{-A s}\left[B a(s)+F_{p}^{c} u^{\prime \prime}(s)\right] d s \\
& a(s)=a_{k} \delta\left(s-t_{k}\right) \Delta t \\
& u^{\prime \prime}(s)=u_{k} " \delta\left(s-t_{k}\right) \Delta t \\
& X_{k+1}=e^{A \Delta t} X_{k}+e^{A \Delta t} B a_{k} \Delta t+e^{A \Delta t} F_{p}^{c} u^{\prime \prime}{ }_{k} \Delta t
\end{aligned}
$$

Note that giving all the information at step $k$, both the displacement and velocity at step $k+1$ is calculated, thus the time integration method is said to be explicit. The problem of the matrix exponential is overcome by the expm function available in MATLAB, which uses a scaling a squaring technique to accurately calculate the coefficient $e^{A \Delta t}$ in eq. (15). In each time step the inelastic displacement $u_{k+1}$ will be calculated and the information will be used to calculate $X_{k+2}$. Figure 2 gives a schematic view of the explicit time integration argorithm implemented.

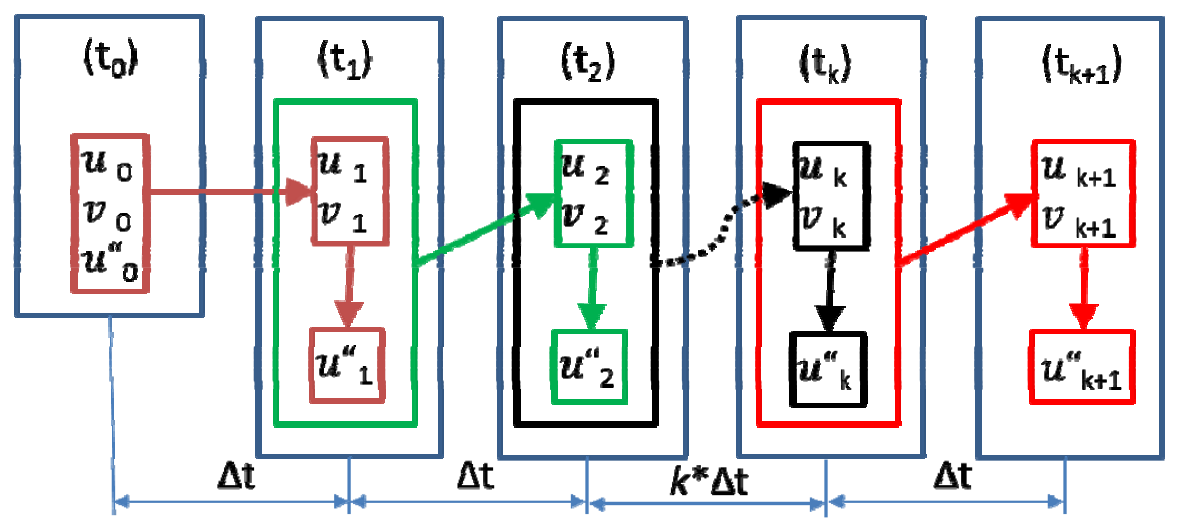

Fig 2 - Explicit time integration used to calculate the structural response

By comparison, refference [15] uses the Force Analogy Method to obtain the structural response of different structural patterns combined with the Wilson-Teta integration method. The integration method being implicit, iterations are required in each time step to solve simultaneosly both the equation of motion and the specific nonlinear inequality $M(t) \leq M_{\text {allowable }}(t)$.

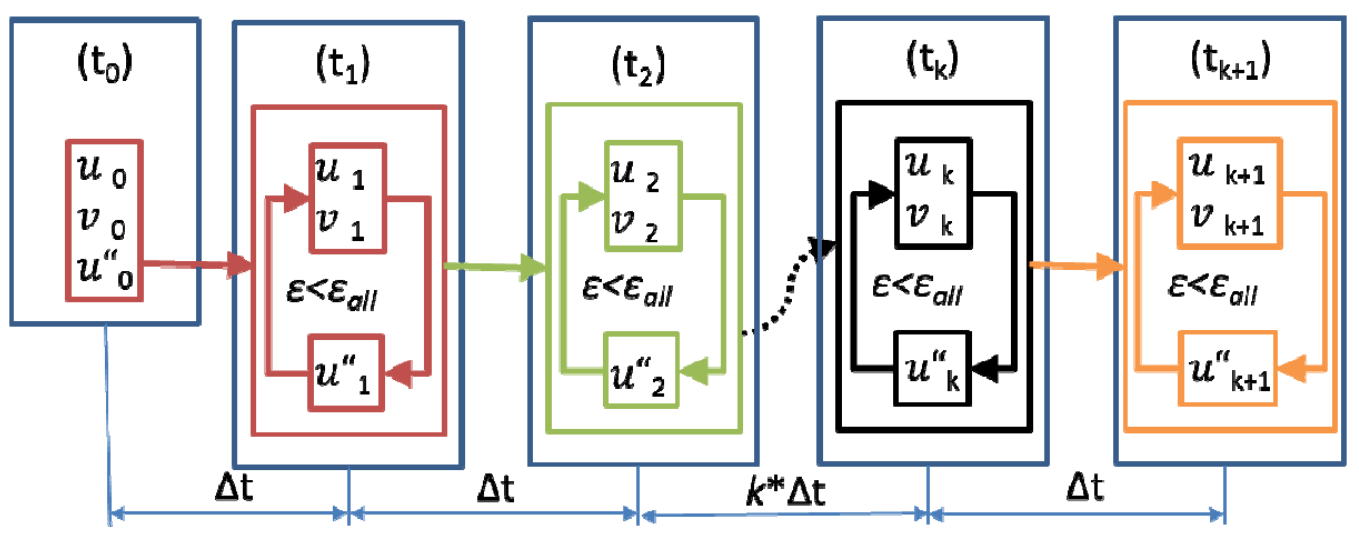

Fig 3 - Explicit time integration used to calculate the structural response

The implicit time integration algorithm used in [15] is given schematically in fig. 3 . Note that once the pounding forces are introduced in the equation of motion, more iterations will be required, because the pounding force, the total displacement and the inelastic displacement will depend one to the other. This is the main reason why an explicit time integration is preffered in this paer instead of an implicit one. Also, the two relations, namely the equation of motion and the bending moment inequality specific for nonlinear problems are decoupled and solved one by 
one, according to Fig.2 . The mathematical explanation of the reason why the bending moment inequality is decoupled of the equation of motion is underlaying in equation (14), where the inelastic displacement $u$ " is aproximated using the backward value. The physical explanation of this issue can be understood judging that the inelastic displacement requires a greater time to be exhibited than the time step, i.e. the inelastic wave velocity is smaller than the loading velocity.

Figure $1 \mathrm{~b}$ gives the calculation procedure for the bending moment, and detailed in equation (16):

$$
M(t)=K_{P}^{T} X(t)-K_{R} \theta^{\prime \prime}(t) \rightarrow M_{k+1}=K_{P}^{T} X_{k+1}-K_{R} \theta^{\prime \prime}{ }_{k+1}
$$

The decomposition depicted in Figure 1a gives the general equation that relates the plastic rotation $\theta^{\prime \prime}$ to the plastic displacement $u^{\prime \prime}$ :

$$
\begin{aligned}
& F_{a}(t)=-F_{R F}(t) \leftrightarrow K_{P} \theta(\mathrm{t})=\mathrm{Ku}(t) \leftrightarrow u(\mathrm{t})=\mathrm{K}^{-1} \mathrm{~K}_{\mathrm{P}} \theta(t) \rightarrow \\
& u^{\prime \prime}{ }_{k+1}=K^{-1} K_{P} \theta^{\prime \prime}{ }_{k+1}
\end{aligned}
$$

In order to compare the results including the pounding forces, first an analysis for two independent structures is performed. The data for the two structures data is tabulated in table 1. The values in table 1 are consistent with the data available in [9] and [11]. Proportional damping (Rayleigh) to the mass and stiffness is used.

\begin{tabular}{|c|c|c|c|}
\hline & $\begin{array}{l}\text { Reference } \\
\text { weak } \\
\text { structure (a) }\end{array}$ & $\begin{array}{l}\text { Reference } \\
\text { stiff } \\
\text { structure (b) }\end{array}$ & \multirow{7}{*}{$\begin{array}{ll}\text { मा } \\
\begin{array}{ll}\text { (a) } & \text { (b) }\end{array}\end{array}$} \\
\hline Mass (kg) & 75000 & 3000000 & \\
\hline Stiffness coefficient $(\mathrm{kN} / \mathrm{m})$ & 2056 & 1316000 & \\
\hline Natural period (s) & 1.2 & 0.3 & \\
\hline Damping ratio & 0.05 & 0.05 & \\
\hline Yield force $(\mathrm{kN})$ & 70 & 4000 & \\
\hline Yield deformation (m) & 0.034 & 0.003 & \\
\hline
\end{tabular}

Table 1

Dynamic characteristics of the reference structures

The first $10 \mathrm{~s}$ of the NS component of El Centro recording is used in this study, and the recording is plotted in Fig. 4. The nonlinear time histories for both structures are plotted in Fig. 5. Figures 6 and 7 illustrate the comparison of the data obtained by state space approach to another explicit solver based on central difference method [11]. The numerical values of the displacement time-history are tabulated in Table 2 presented in the appendix for comparison reasons. The values presented are obtained for timestep $\Delta t=0.005 \mathrm{~s}$.

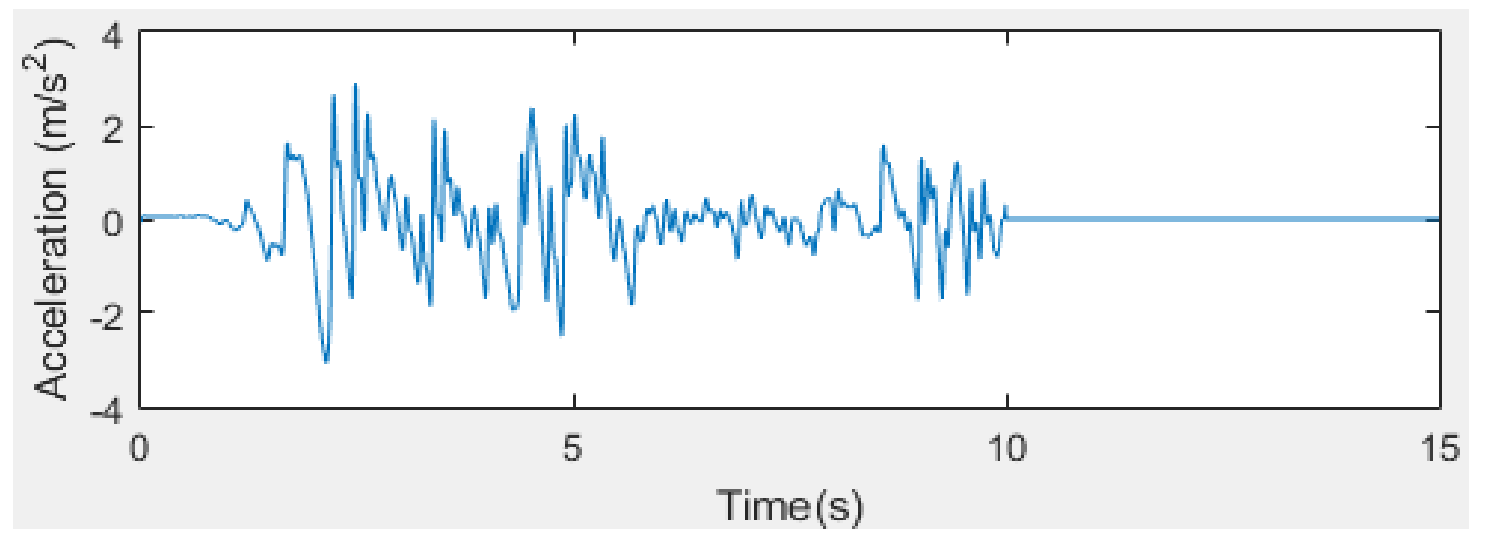

Fig. 4 - First 10s of NS component of El Centro Recording used in this paper 


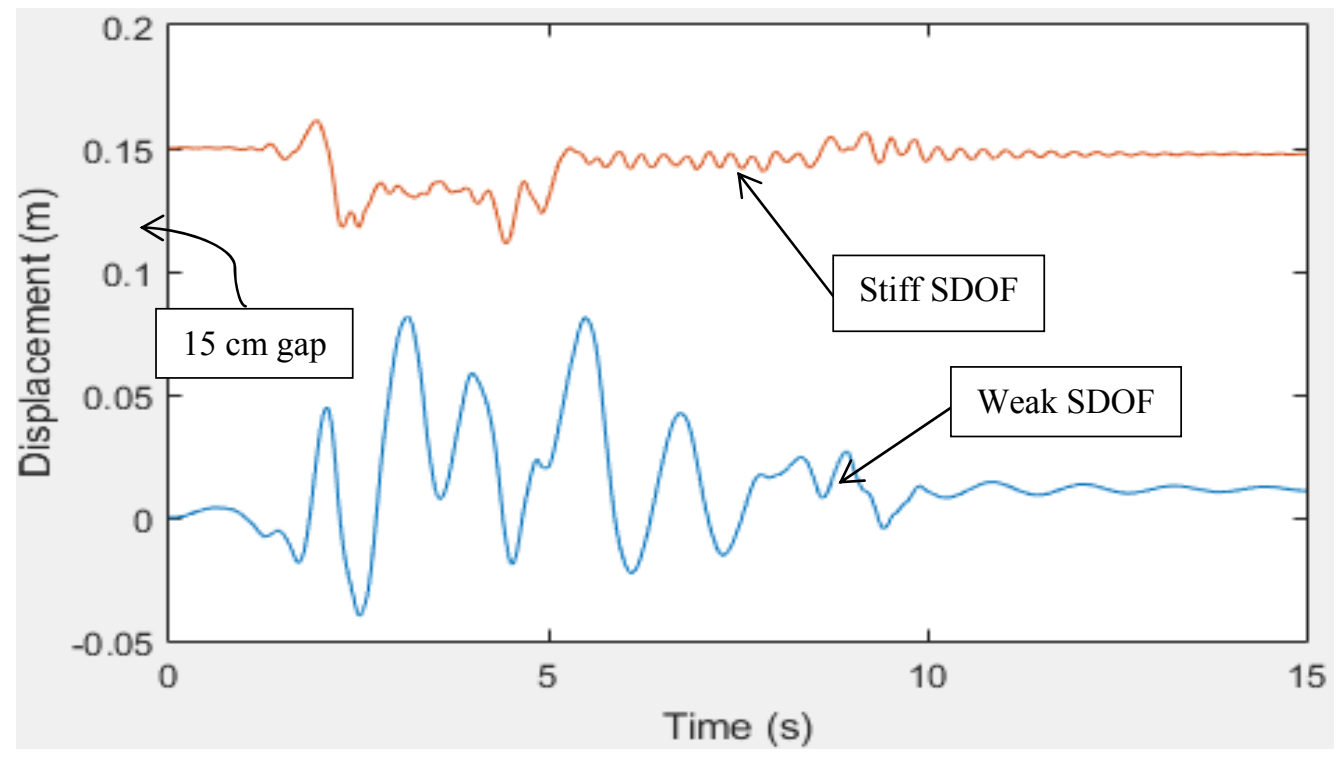

Fig.5 - Nonlinear time histories under the first $10 \mathrm{~s}$ of the NS component of the El Centro recording for both SDOF's

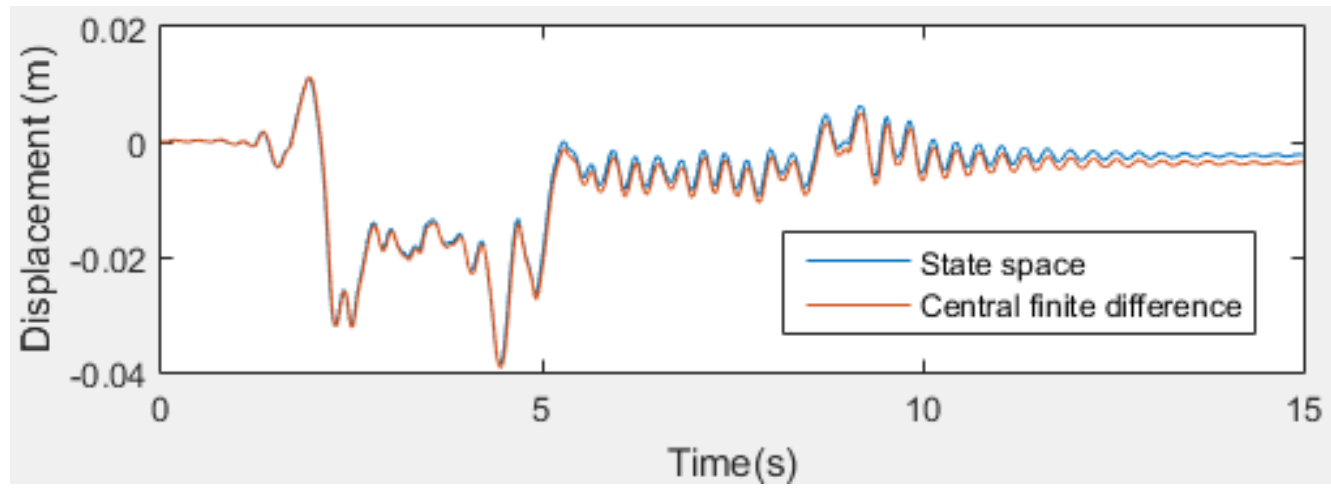

Fig.6 - Nonlinear time histories for the stiff SDOF

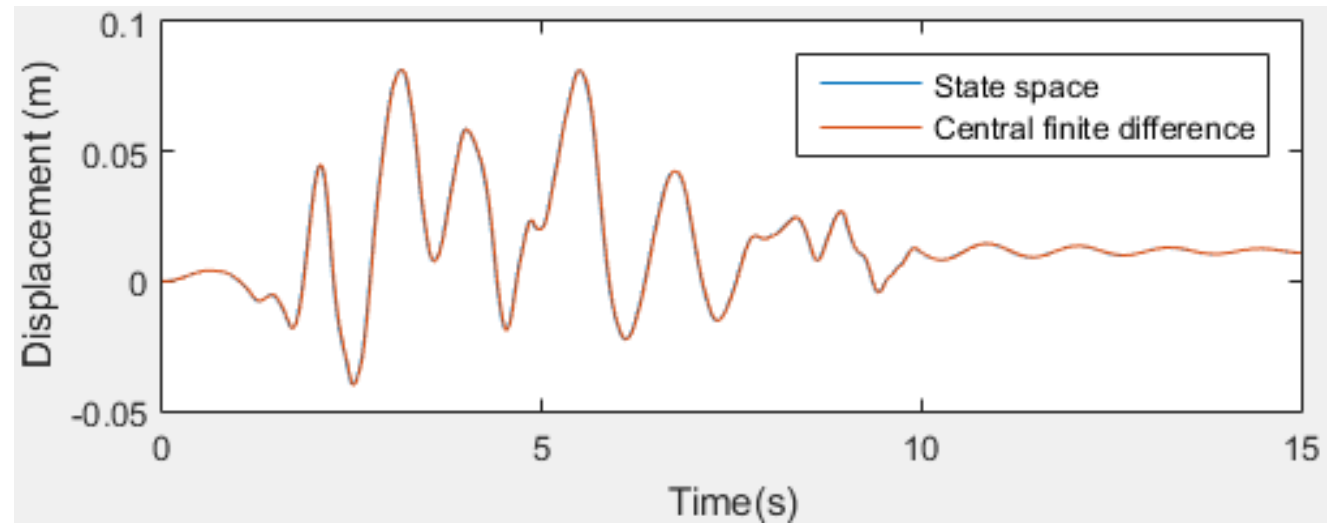

Fig.7 - Nonlinear time histories for the weak SDOF

\section{Structural pounding between two adjacent structures}

In this chapter the nonlinear viscoelastic impact element is employed and the values are compared with the data presented in [11]. The refference data in [11] is obtained with stereomechanics aproach as well as the nonlinear viscoleastic impact element, but with another time integration method, i.e. the finite central difference method. The two structures are considered to be in the close proximity, i.e a gap distance equal to $3 \mathrm{~cm}$ is used, as it was used in [9]. Again, the major difference is the time integration method - in reference [9] the Newmark implicit time integration is used - and the comparison with the stereomechanics approach. 
Not only the mass, but also on the surface geometry, material properties, prior impact velocities and material history influence the pounding force time history [9]. Table 3 summarizes the pounding forces during approach period $\boldsymbol{F}^{\boldsymbol{a}}(\boldsymbol{t})$ and restitution period $\boldsymbol{F}^{\boldsymbol{r}}(\boldsymbol{t})$. The deformation of colliding structural elements is represented by $\boldsymbol{\delta}(\boldsymbol{t})$.

Table 3

Expression of the pounding forces in the nonlinear viscoelastic model [9]

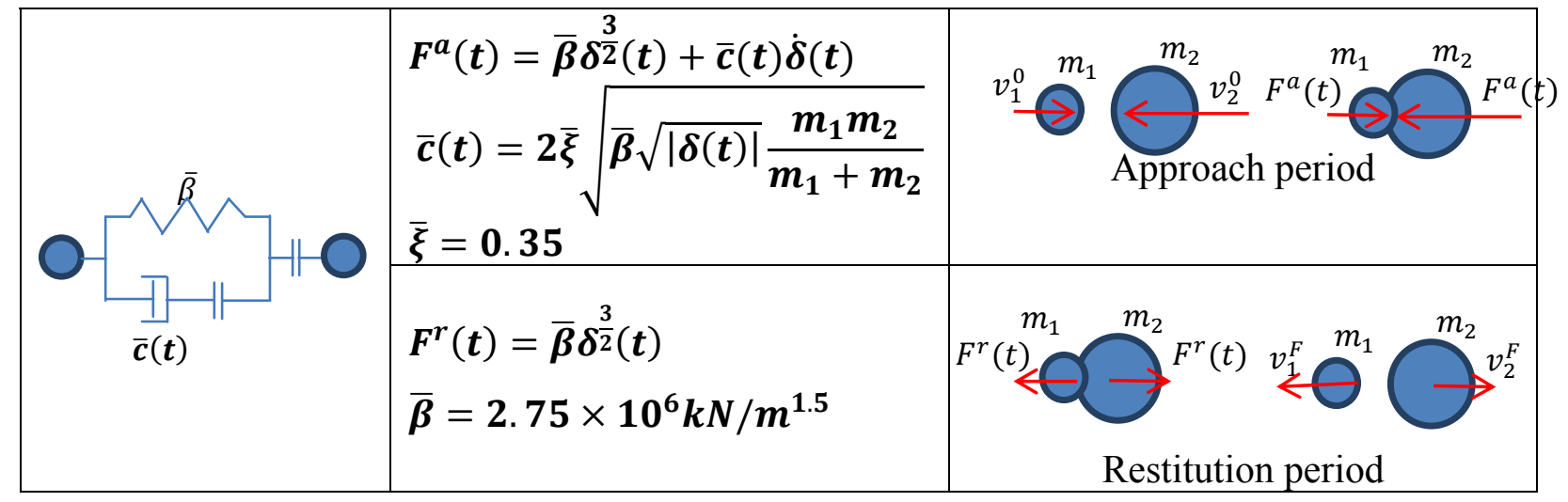

The pounding force $\boldsymbol{F}^{\text {pounding }}$ obtained using the relations from table 3 is added to equation (8), obtaining equation (18):

$$
M \ddot{u}+C \dot{u}+K u=-M a(t)+K u^{\prime \prime}(t)+F^{\text {pounding }}
$$

Further, the state space representatin is employed, and equation (11) becomes (19). Equation (20) is the solution of (19). Equation (21) is the representation of the pounding force with Delta forcing function. Further, using equations (21) and (15), one will obtain the solution in the time domain as a explicit recursive equation (22):

$$
\begin{gathered}
\dot{X}=\left[\begin{array}{c}
\dot{u} \\
\ddot{u}
\end{array}\right]=\left[\begin{array}{cc}
0 & \mathrm{I} \\
-M^{-1} K & M^{-1} C
\end{array}\right]\left[\begin{array}{l}
u \\
\dot{u}
\end{array}\right]+\left[\begin{array}{c}
0 \\
-1
\end{array}\right] a+\left[\begin{array}{c}
0 \\
M^{-1} K
\end{array}\right] u^{\prime \prime}+\left[\begin{array}{c}
0 \\
M^{-1}
\end{array}\right] F^{\text {pounding }} \leftrightarrow \\
\dot{X}=A X+B a+F_{p}^{c} u^{\prime \prime}+B_{p} F^{\text {pounding }} \\
X(t)=e^{A\left(t-t_{0}\right)} X\left(t_{0}\right)+e^{A t} \int_{t_{0}}^{t} e^{-A s}\left[B a(s)+F_{p}^{c} u^{\prime \prime}(s)+B_{p} F^{\text {pounding }}(s)\right] d s \\
F^{\text {pounding }}(s)=F_{k}^{\text {pounding }} \delta\left(s-t_{k}\right) \Delta t \\
X_{k+1}=e^{A \Delta t} X_{k}+e^{A \Delta t} B a_{k} \Delta t+e^{A \Delta t} F_{p}^{c} u^{\prime \prime}{ }_{k} \Delta t+e^{A \Delta t} B_{p} F_{k}^{\text {pounding }} \Delta t
\end{gathered}
$$

With the calcultated displacement $\boldsymbol{u}_{\boldsymbol{k}+\boldsymbol{1}}$ the check of the collision is performed and if it exist, addtitional forces are calculated. The schematic representation of the explicit time integration method is depicted in Fig. 8a. In each time step both the inelastic displacement is checked and calculated and the collision check is performed. The values obtained in each step are further used in the following step.

Figure $8 \mathrm{~b}$ shows a schematic representation of what operations an implicit time integration method would require in each step. The iterations performed would result in a less computational efficiency compared to an explicit time integration method. One such example is the algorithm proposed in [16], where a smaller time step is chosen compared to the initial timestep when collision is detected, i.e. a trial is performed in each timestep to estimate whether a collision would exist or no in that step, and if exist the timestep is lowered. A sub-iteration is thus proposed and performed in [16] if the collision is detected, in order to obtain the exact collision time. 


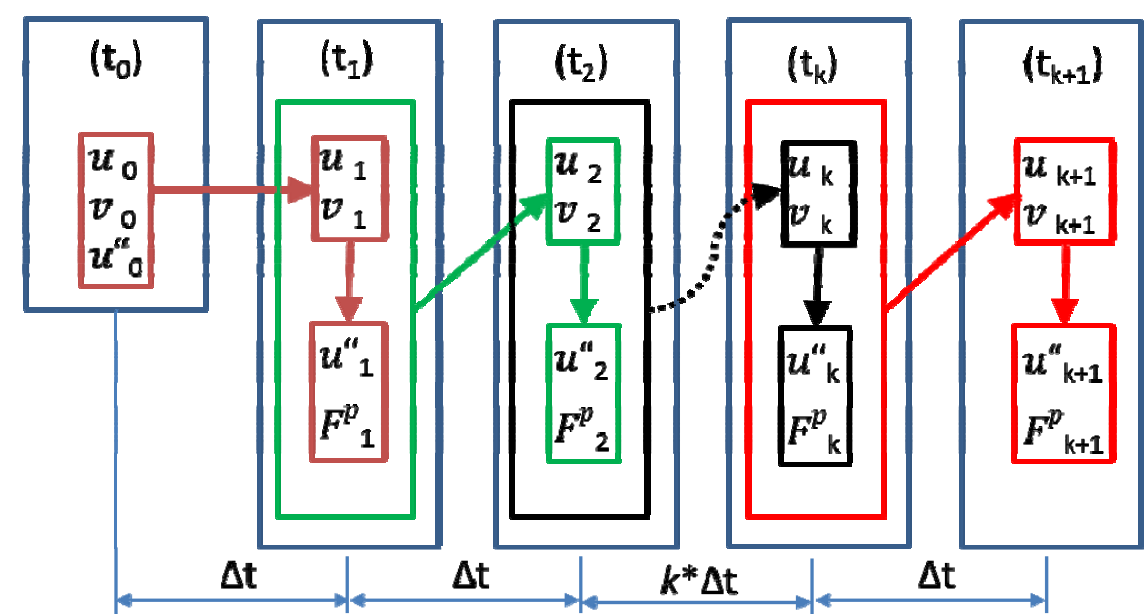

Fig. 8a - Explicit time integration method developed in this paper to account for structural pounding

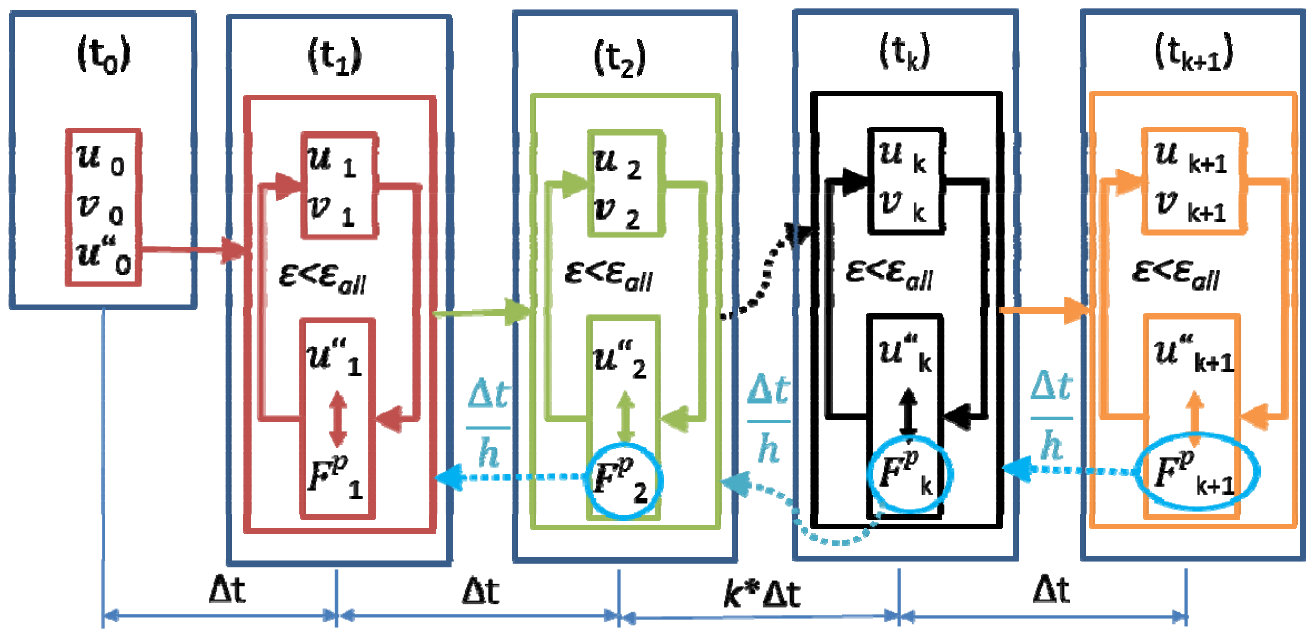

Fig. 8b - Schematic representation of an implicit time integration to account for structural pounding

Fig. 9 illustrates the displacement time-history of the two structures for the $3 \mathrm{~cm}$ gap considered, while in the right side of the time-history representation the displacement values are given at different time intervals.

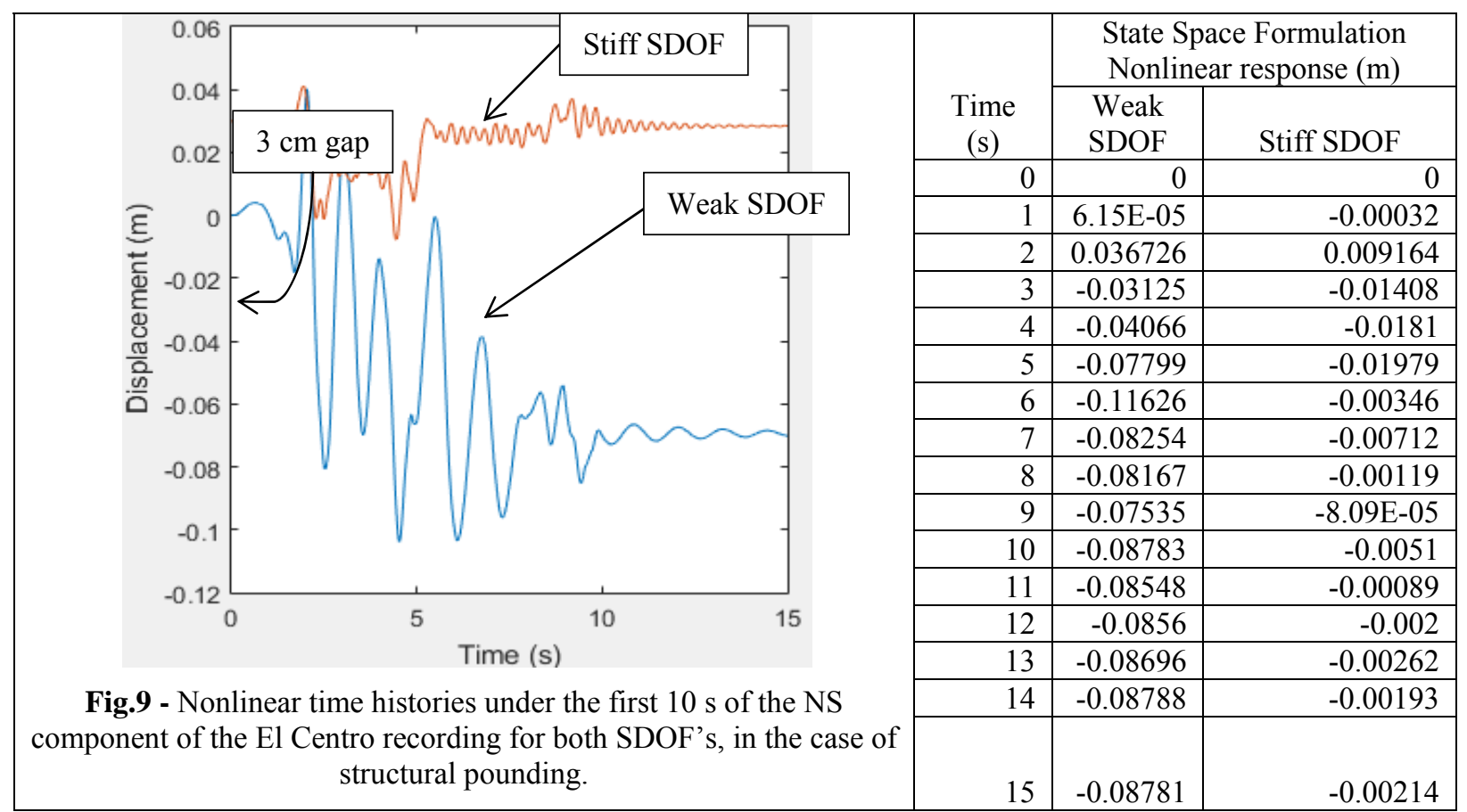


Figure 10 illustrates the pounding force time history. Two collisions are detected and the values of the pounding forces are tabulated. The transferred momentum, calculated as the area under the impact forces time history, is $H_{\text {nonlin }, 1}^{\text {nonlisco }}=12.61 \mathrm{kN} * \mathrm{~s}$, for the first collision, and $H_{\text {nonlin }, 2}^{\text {nonlisco }}=10.82 \mathrm{kN} * S$ for the second collision. The total transferred momentum is $H_{\text {nonlin }, 1+2}^{\text {nonlis }}=23.43 k N * S$

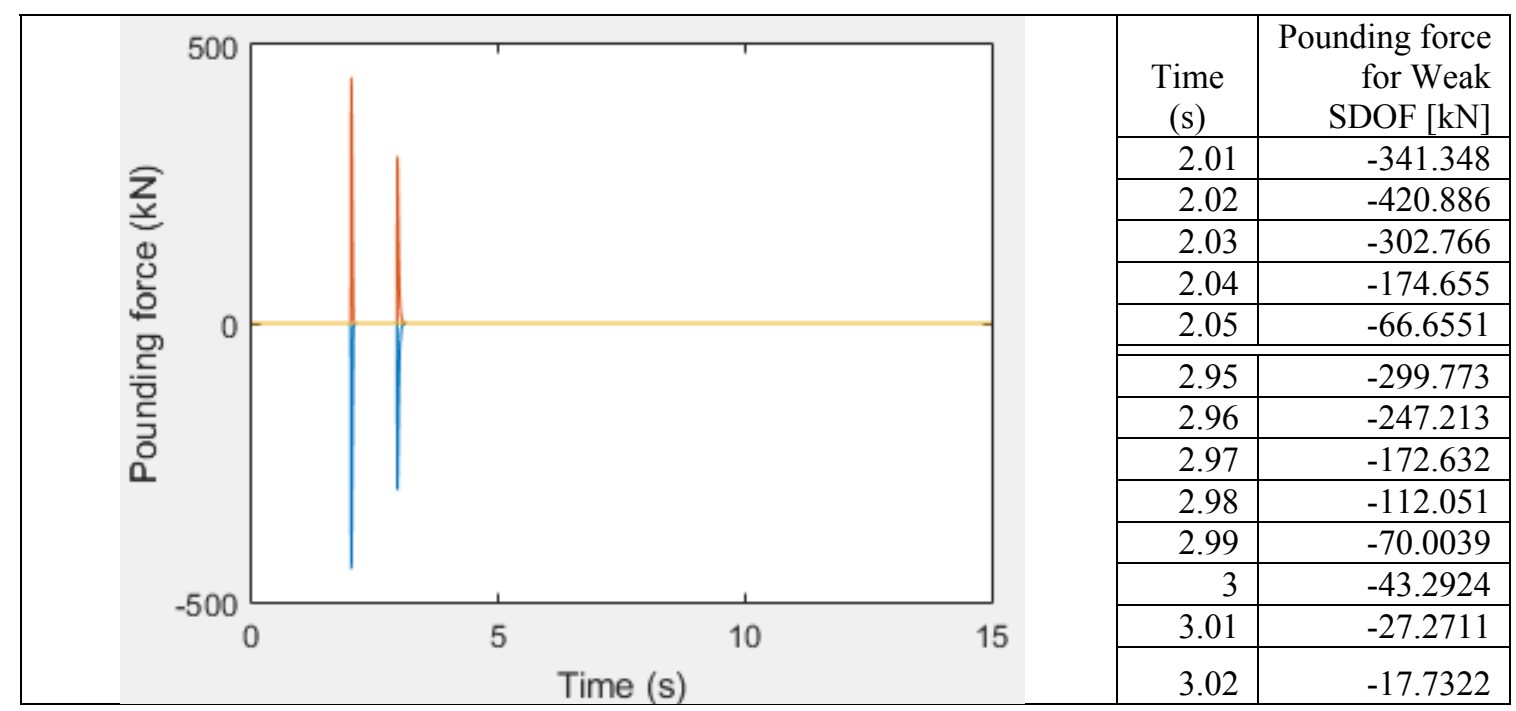

Fig.10 - Pounding force time history obtained with direct integration the state-space formulation and the nonlinear viscoelastic impact element.

\subsection{Comparison between the analyzed model and liteature data.}

Fig. 11 illustrates the displacement time-history in comparison with the displacement timehistory obtained by central finite difference method [11], which is another explicit time integration method. The displacement time-history of the two structures is basically the same, the only difference is that this paper two collisions are detected. For the stiff SDOF the same timehistory is obtained, while for the weak SDOF, the two-step collision leads to a $\sim 15 \%$ difference is the residual displacement.

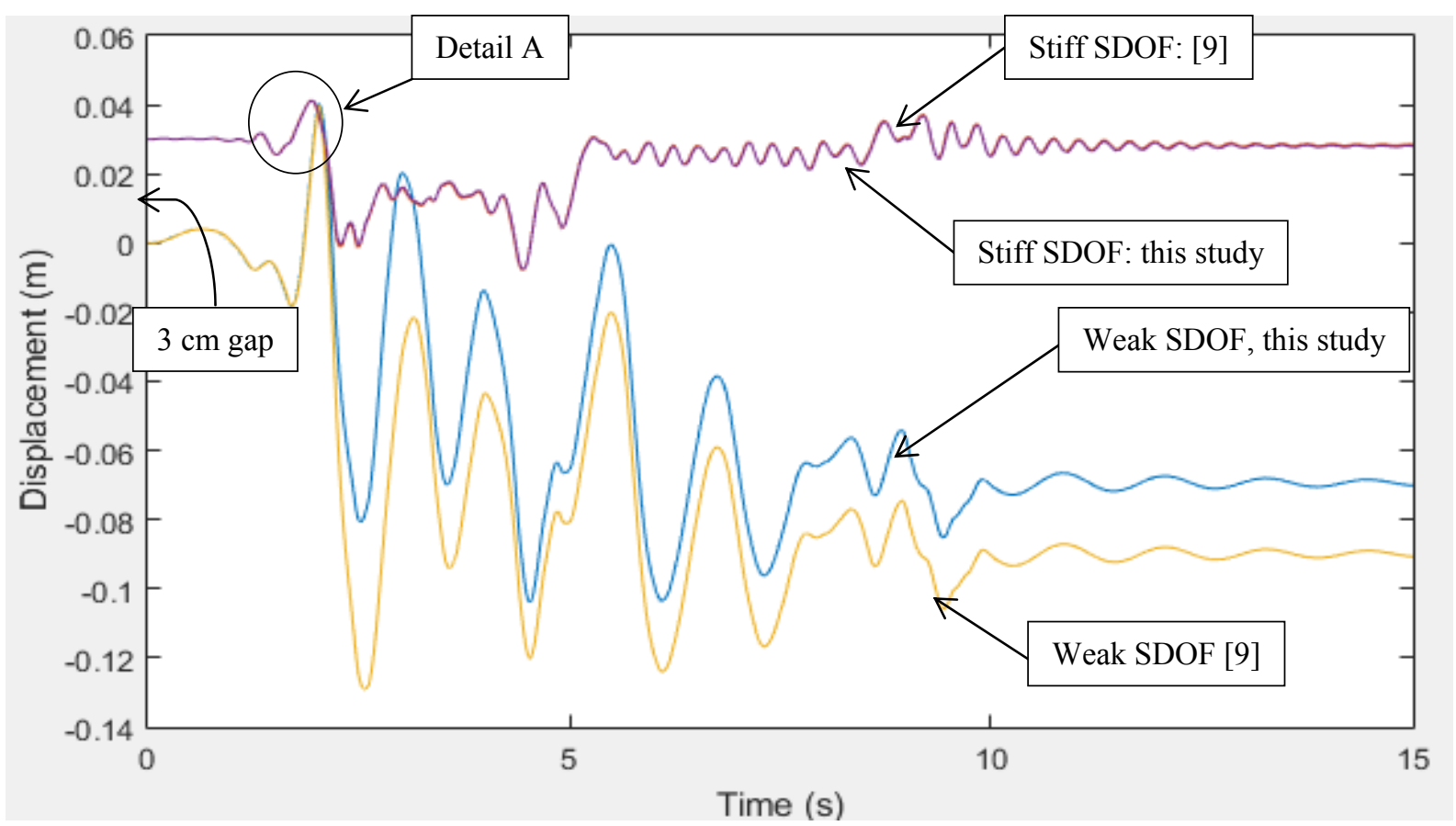

Fig.11 - Comparison between the displacement time history obtained in this study and the values presented in [11] 
The peak value of the first collision obtained in this paper is smaller than the one presented in [11]. From the point of view of the total transferred momentum, in this paper was obtained $H_{\text {nonlin, } 1+2}^{\text {nonlin visco }}=23.43 \mathrm{kN} * S$, which is very close value to the one reported in [11], i.e, while in paper [9] is $H_{\text {nonlin }}^{\text {nonlisco }}=24.35 \mathrm{kN} * \mathrm{~s}$. The conclusion is that although the number of collisions is different, the same total momentum is transferred between structures and the same residual displacement is obtained at the end of the

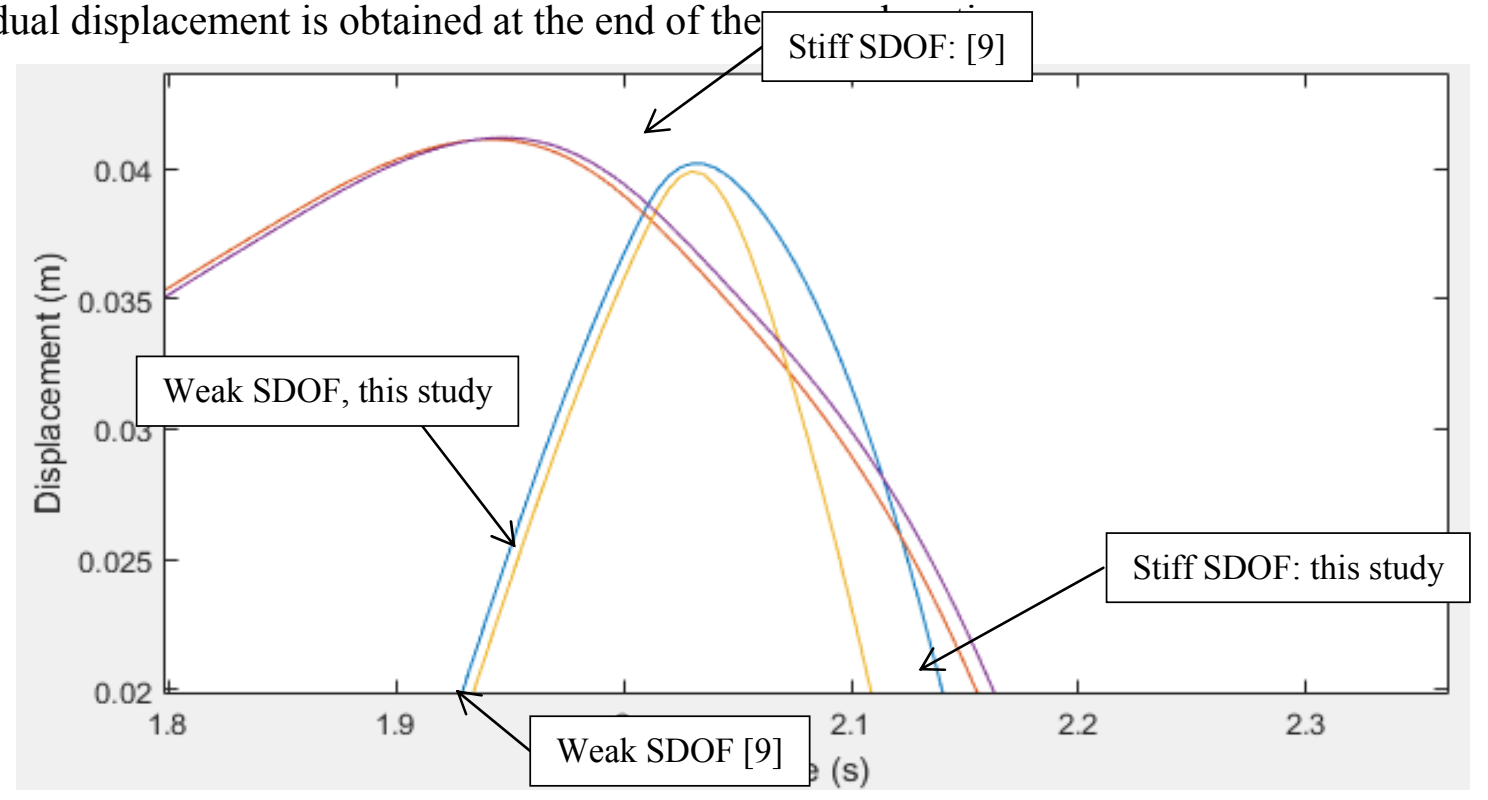

Fig.12 - Detail A: First collision duration

\subsection{The influence of different earthquake recordings}

The use of other ground motion recording having various frequency contents is further investigated. The 1977 Vrancea N-S earthquake recording is used and illustrated in Fig. 13. First, no collision is considered, i.e. the gap between the structures is considered $18 \mathrm{~cm}$. Consequently, the nonlinear time history of the two SDOF is plotted in Fig. 14.

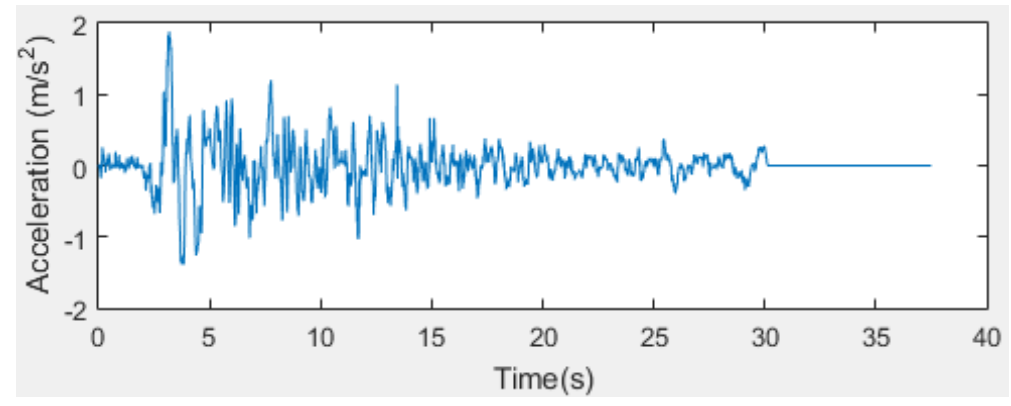

Fig. 13 - First 30 s of NS component of 1977 Vrancea recording

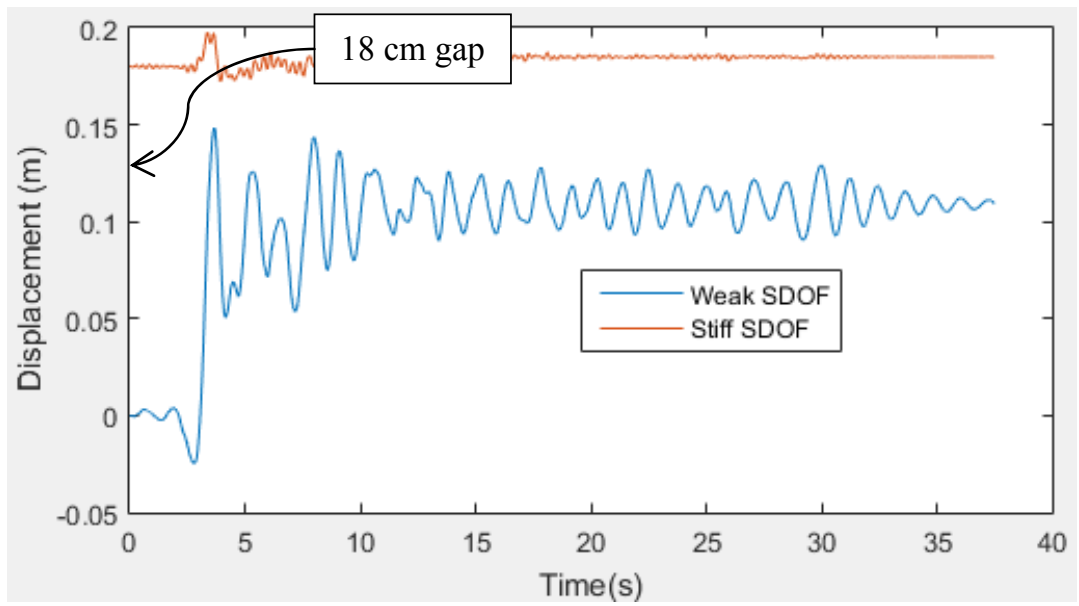

Fig. 14 - Nonlinear time histories under the first 30 s of 1977 Vrancea recording for both SDOF's 
The gap distance is lowered to $3 \mathrm{~cm}$ and the stereomechanical approach is employed. Figure 15 illustrates the displacement time history of the two SDOF for a $3 \mathrm{~cm}$ gap distance. Finally, the nonlinear viscoelastic impact element is employed to obtain the displacement time history. Comparing figures 15 and 16, one observes a good match for the considered cases. The minor tangling observed when the impact element is considered is due to the fact that some deformation is allowed to the colliding bodies (see table 3 ). The corresponding pounding forces are plotted in figure 17-18. Although the peak value of the pounding force is highly different in the stereomechanical approach and nonlinear viscoelastic impact element approach, the same number of collisions and collision time is registered. The corresponding linear momentum transferred through the collision is the same order of magnitude, namely $H^{\text {nonlin visco }}=$ $27.1 k N * s$.

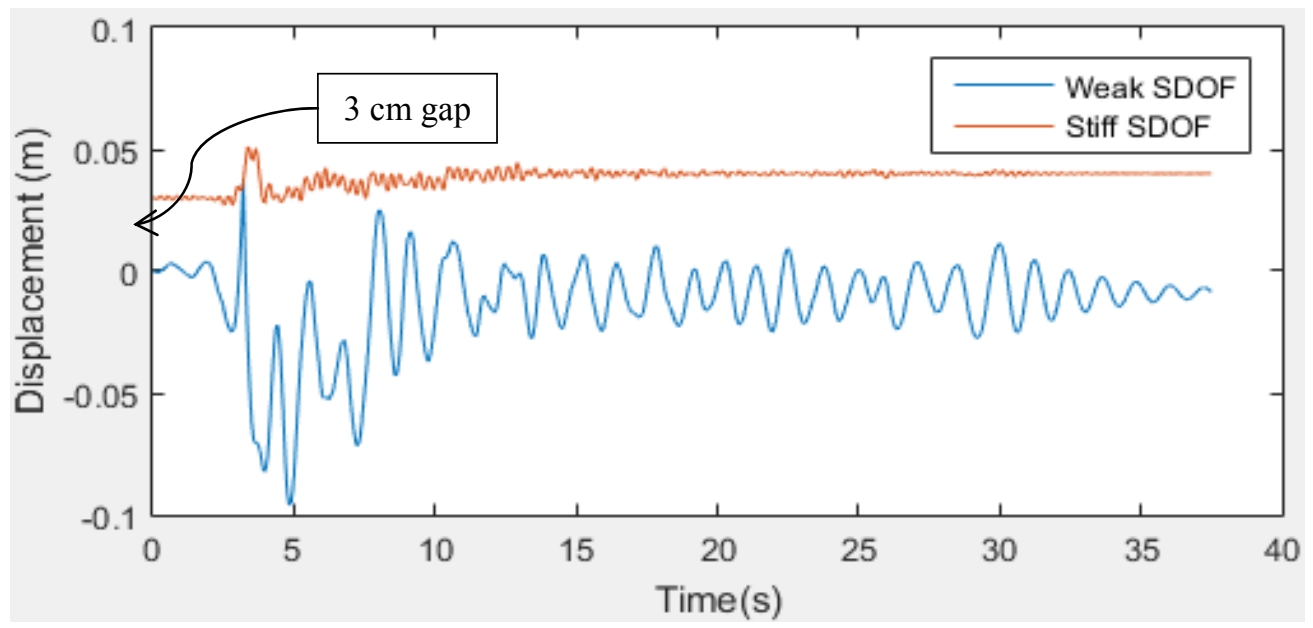

Fig. 15 - Displacement time histories obtained using the stereomechanical approach

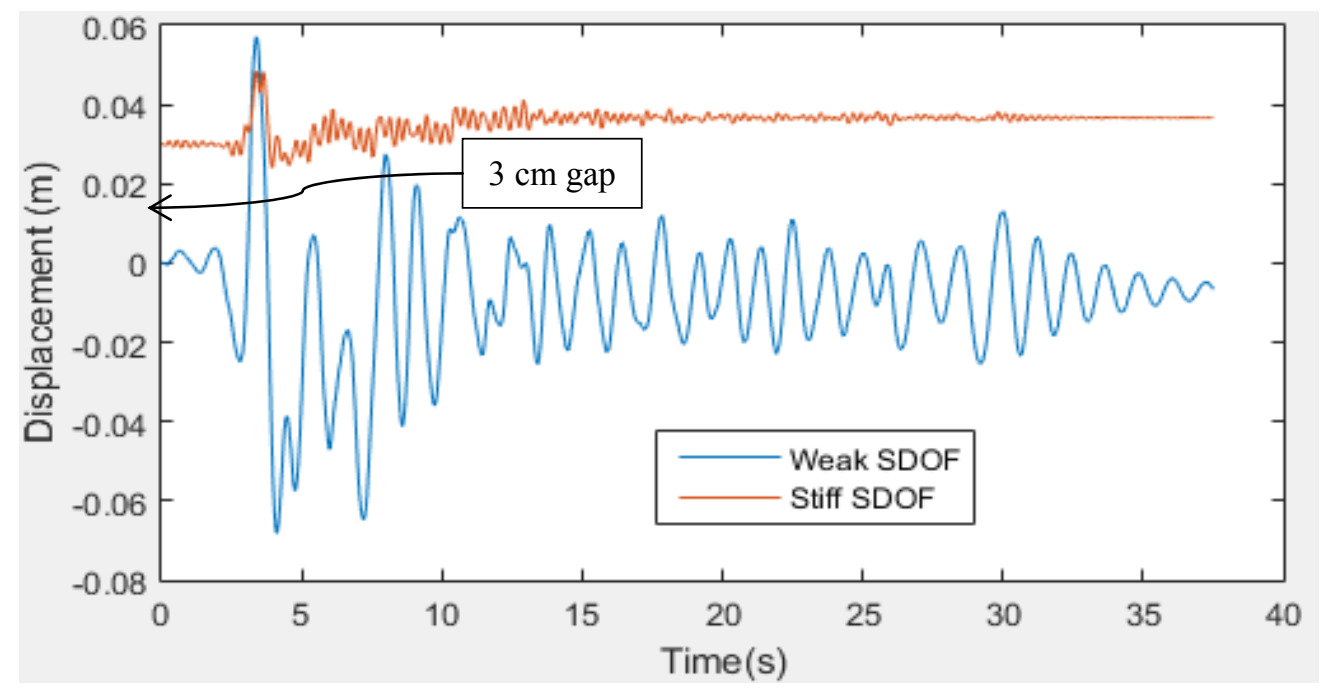

Fig. 16 - Displacement time histories obtained using the nonlinear viscoelastic impact element

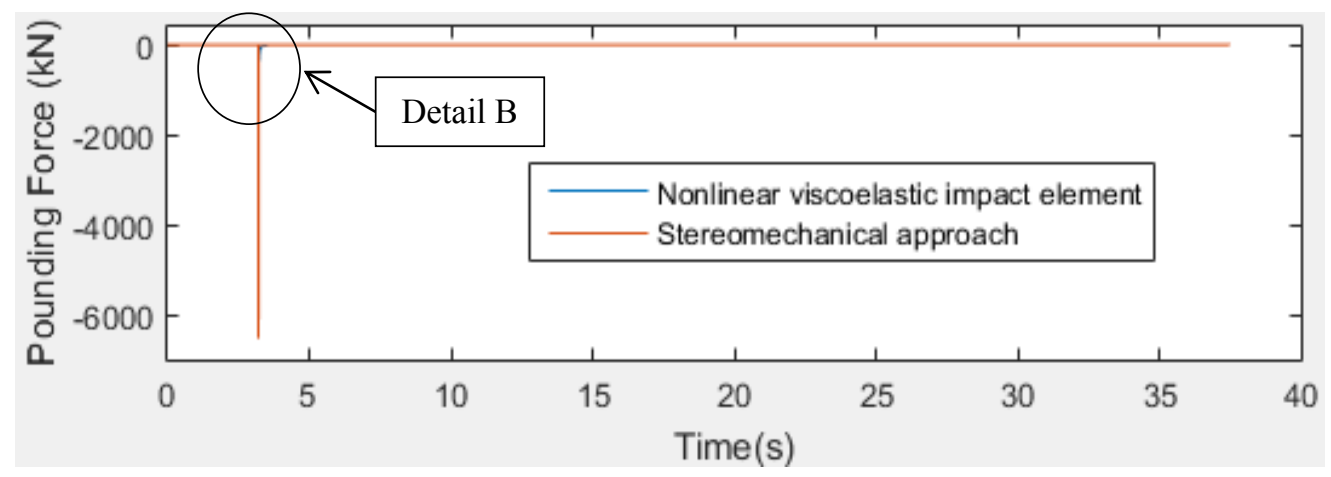

Fig. 17 - Pounding force time histories 


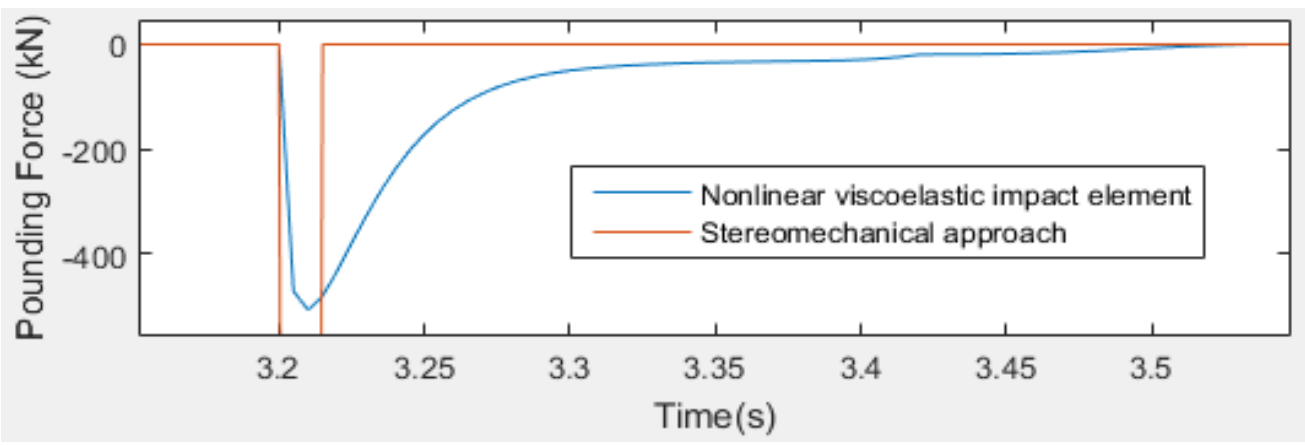

Fig. 18 - Detail B: Pounding force time histories

\section{Conclusions}

In this paper the pounding forces are modeled using the nonlinear viscoelastic impact element. Using the state space representation, an explicit time integration method is developed in a MATLAB code. In the first part of the paper the state space formulation and the direct integration is presented. The nonlinear structural response for the two SDOF structures is calculated using the Force Analogy Method. To that extent the authors developed a routine in MATLAB which has been validated with results from reference [9] and [11].

Chapter 3 of the study, implements a nonlinear viscoelastic impact element which models accurately the pounding forces. As previously shown [11], the result of the using of the nonlinear viscoelastic impact element is a significant decrease of the peak value of the pounding forces with respect to the stereomechanical model. Although the pounding force is reduced by an order of magnitude, the transferred momentum suffers only a slight reduction of about $20 \%$. The Delta function is used to represent the pounding force in the state space formulation, leading to an explicit time integration procedure. The state space formulation, along with the Force Analogy Method and nonlinear viscoelastic impact element prove to be computationally efficient.

Thus, the displacement time history, first collision time and duration and the overall residual displacement are correctly predicted. The only difference, i.e. two collisions instead of one, is not a significant difference because the total transferred momentum is the same as the reference one. The reason of this difference is a result of the different peak values of the pounding force calculated in the first collision, which mean a smaller quantity of energy is transferred between the two structures. Thus, the weak SDOF undergoes a smaller inelastic displacement after the first collision compared to the reference study. The result of the smaller quantity of transferred energy is that a second collision is detected where another quantity if energy is transferred making the model developed in this study comparable with the reference one.

In this paper the earthquake was considered as acting from left to right, so the research in the article can be continued by considering the directionality effect of the earthquake. A second earthquake recording is used to analyze the pounding effects. Future work may investigate the effect of different frequency content recordings. A MDOF model would represent more accurately the effect of pounding on regular structures. The state space approach has the main advantage that control procedures can be easily implemented in the case of structural problems.

\section{References}

[1] Cole G.L., Dhakar R.P. Turner F.M. (2012) Building Pounding damages observed in the 2011 Christchurch earthquake, Earthquake Engineering \& Structural Dynamics 41(5):893-913 DOI: 10.1002/eqe.1164

[2] Shrestha B., Hao H. (2018) Building Pounding Damages Observed during the 2015 Gorkha Earthquake, Journal of Performance of Constructed Facilities Vol. 32, Issue 2, ISSN (online): 1943-5509

[3] Anagnostopoulos, S. A. (1988). Pounding of buildings in series during earthquakes. Earthquake Engineering and Structural Dynamics. 16, 443-456. 
[4] Mate N. U., Bakre S. V., Jaiswal O. R. (2012). Comparative Study of Impact Simulation Models for Linear Elastic Structures in Seismic Pounding. Proceedings of the fifthteen ${ }^{\text {th }}$ world conference on earthquake engineering. Lisbon, Portugal

[5] Mate N. U., Bakre S. V., Jaiswal O. R. (2014). Seismic pounding of adjacent linear elastic buildings with various contact mechanisms for impact simulation. Asian journal of civil engineering. vol. 16, no. 3, 383-415

[6] Jankowski R. (2004). Non-linear viscoelastic model of structural pounding. 13th World Conference on Earthquake Engineering Vancouver, Canada. Paper No. 3082

[7] Mahmoud S., Jankowski R. (2011). Modified Linear Viscoelastic model of earthquake-induced structural pounding. IJST, Transactions of Civil and Environmental Engineering. Vol. 35, 51-62

[8] Jankowski R. (2007). Theoretical and experimental assessment of parameters for the non-linear viscoelastic model of structural pounding. Journal of theoretical and applied mechanics. Vol. 4, 931-942

[9] Jankowski R., Mahmoud S. (2015) Earthquake-Induced Structural Pounding. Switzerland: Springer International Publishing.

[10] Mate N. U., Bakre S. V., Jaiswal O. R. (2016). Seismic Pounding Response of Singled-Degree-of-Freedom Elastic and Inelastic Structures Using Passive Tuned Mass Damper. International Journal of Civil Engineering(IJCE), DOI 10.1007/s40999-017-0178-7

[11]Nica G.B., Pricopie A,G. (2017) Evaluation of the pounding forces during earthquake using explicit dynamic time integration method. Mathematical Modelling in Civil Engineering, Vol. 13, No.3,21-39

[12] Clough R.W., Penzien J. (1975) Dynamics of structures U.S.A. McGraw-Hill

[13] Hart G.C., Wong K. (1999) Structural dynamics for structural engineers, U.S.A. John Wiley \& Sons

[14] Li G., Wong K. (2014) Theory of nonlinear structural analysis, Singapore. John Wiley \& Sons

[15] Peticila D. (2011) Nonlinear dynamic analysis of plane frames using the force analogy method, Master Disertaion (in romanian), Technical University of Civil Engineering, Bucharest

[16] Balcu M. (2003) Probleme actuale in mecanica solidului deformabil cu aplicatii in constructii, Editura MatrixRom, ISBN 973-685-702-6

\section{Appendix}

Table 2

Comparison between the nonlinear response of the two structures ( no pounding considered )

\begin{tabular}{|c|c|c|c|c|c|}
\hline \multirow{2}{*}{ Time (s) } & \multicolumn{2}{|c|}{ Finite Difference Method [9] } & \multicolumn{2}{c|}{ State Space formulation } \\
\cline { 2 - 5 } & $\begin{array}{c}\text { Weak SDOF } \\
(\mathbf{m})\end{array}$ & Stiff SDOF (m) & Weak SDOF (m) & Stiff SDOF (m) \\
\hline 0 & 0 & 0 & 0 & 0 \\
\hline 1 & 0.000637 & -0.00044 & 0.000121 & -0.00033 \\
\hline 2 & 0.032648 & 0.010405 & 0.036733 & 0.008991 \\
\hline 3 & 0.066989 & -0.01646 & 0.070426 & -0.01541 \\
\hline 4 & 0.058457 & -0.01835 & 0.058593 & -0.01934 \\
\hline 5 & 0.020104 & -0.02334 & 0.020477 & -0.02052 \\
\hline 6 & -0.0156 & -0.004 & -0.01752 & -0.00386 \\
\hline 7 & 0.019669 & -0.00949 & 0.016202 & -0.00753 \\
\hline 8 & 0.016788 & -0.00338 & 0.017061 & -0.0014 \\
\hline 9 & 0.025369 & -0.00146 & & 0.023344 & -0.00024 \\
\hline 10 & 0.01139 & -0.00683 & 0.010882 & -0.00533 \\
\hline 11 & 0.014038 & -0.00326 & & 0.013632 & -0.00125 \\
\hline 12 & 0.013508 & -0.00329 & & 0.013412 & -0.00211 \\
\hline 13 & 0.011675 & -0.00435 & & 0.011761 & -0.00287 \\
\hline 14 & 0.010633 & -0.00373 & & 0.010682 & -0.0022 \\
\hline 15 & 0.010871 & -0.00377 & & 0.010797 & -0.00234 \\
\hline
\end{tabular}

